\title{
A Single Centre Experience in Deep Vein Thrombosis: Frequency of Thrombophilia, Chemotherapy AGENTS AND MALIGNANT CONDITIONS
}

Mihnea-Alexandru Găman ${ }^{1}$, Elena-Codruța Dobrică ${ }^{1}$, Matel Alexandru Cozma ${ }^{1}$, Amelia Maria Găman ${ }^{2}$, Camelia Cristina Diaconu ${ }^{3}$

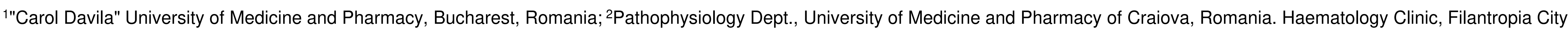

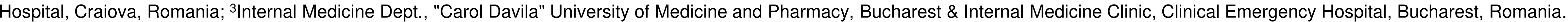

\section{CONTEXT}

Deep vein thrombosis (DVT) is investigated by Doppler ultrasound as the standard investigation of choice. However, clinical probability scores and experience should not be neglected when requesting this examination. Thrombophilia and the use of chemotherapeutic agents are risk factors for DVT Malignancy (cancer) with/without treatment within 6 months or palliative is considered in the Wells criteria for DVT, whereas active malignant conditions (solid/hematological) currently active/considered cured $<1$ year are considered in the Geneva score for pulmonary embolism (PE).

\section{OBJECTIVE}

To describe the characteristics/management of DVT patients admitted in a referral emergency hospital in Romania and evaluate the utility of Doppler ultrasound and clinical probability scores.

\section{PATIENTS}

We conducted a retrospective study of DVT cases diagnosed in our hospital between 01/01/2017 and 21/07/2017. Patients were identified by a database search of diagnostic codes of discharge diagnoses. Data were retrieved from medical records.

\section{RESULTS}

Two patients (moderate risk) and five patients (high risk) were diagnosed with PE. Doppler ultrasound was chosen in $95.92 \%$ of cases and computed tomography in $46.94 \%$. D-dimer test was: positive in $10.20 \%$, negative in $0.04 \%$, untested in $89.76 \%$ of in $10.20 \%$, negative in $0.04 \%$, untested in $89.76 \%$ of cases.

\begin{tabular}{|c|c|}
\hline DVT patients & No. (\%) \\
\hline Study group & $49(100 \%)$ \\
\hline Females & $27(55.1 \%)$ \\
\hline Males & $22(44.9 \%)$ \\
\hline Mean age & 60.4 years \\
\hline Range & $29-84$ years \\
\hline
\end{tabular}

\begin{tabular}{|c|c|}
\hline Most common symptoms & No. (\%) \\
\hline Unilateral leg pain & $45(91.84 \%)$ \\
\hline Pain on limb palpation & $42(85.71 \%)$ \\
\hline Fever & $5(10.20 \%)$ \\
\hline Substernal chest pain & $5(10.20 \%)$ \\
\hline $\begin{array}{c}\text { Wells clinical score for DVT } \\
\text { probability }\end{array}$ & No. (\%) \\
\hline High probability & $44(89.90 \%)$ \\
\hline Moderate probability & $5(10.20 \%)$ \\
\hline Low probability & $0(0.00 \%)$ \\
\hline
\end{tabular}

B-mode ultrasound: thrombus in the popliteal vein ${ }^{1}$; thrombus in the left common femoral vein ${ }^{2}$. Color Doppler ultrasound: thrombus in the right great saphenous vein ${ }^{3}$. Computed tomography in $\mathrm{PE}^{4,5}$.

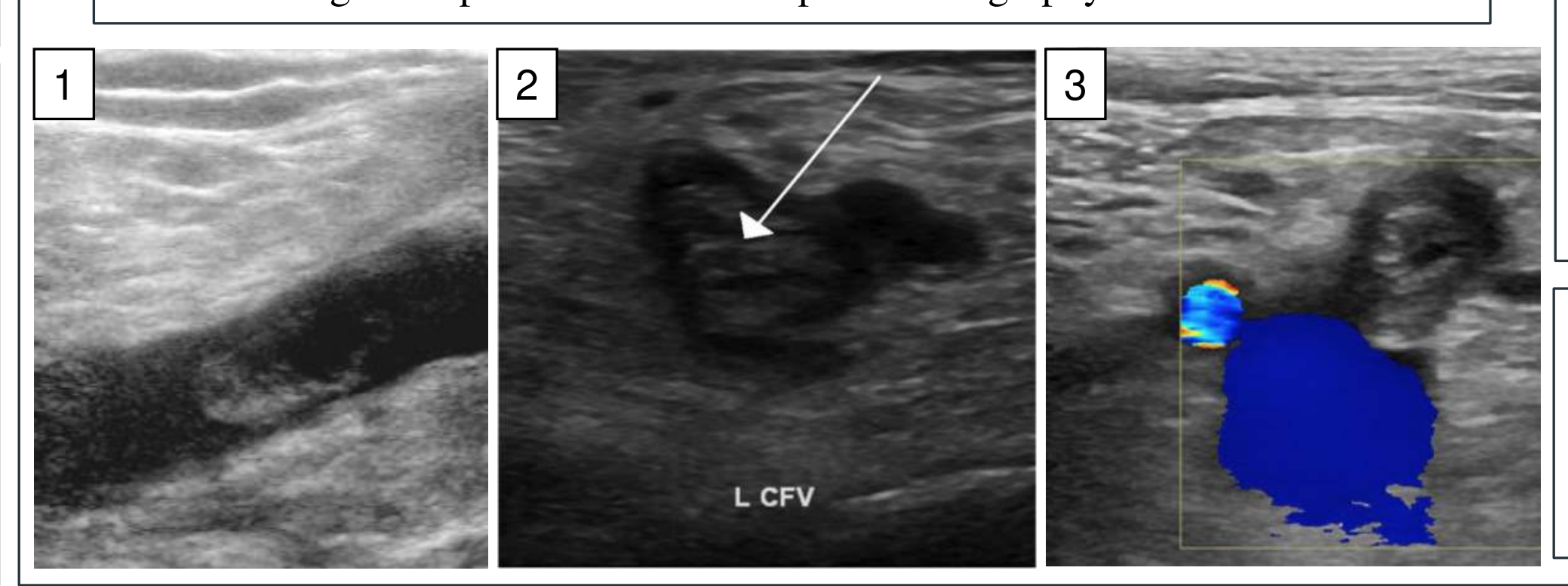

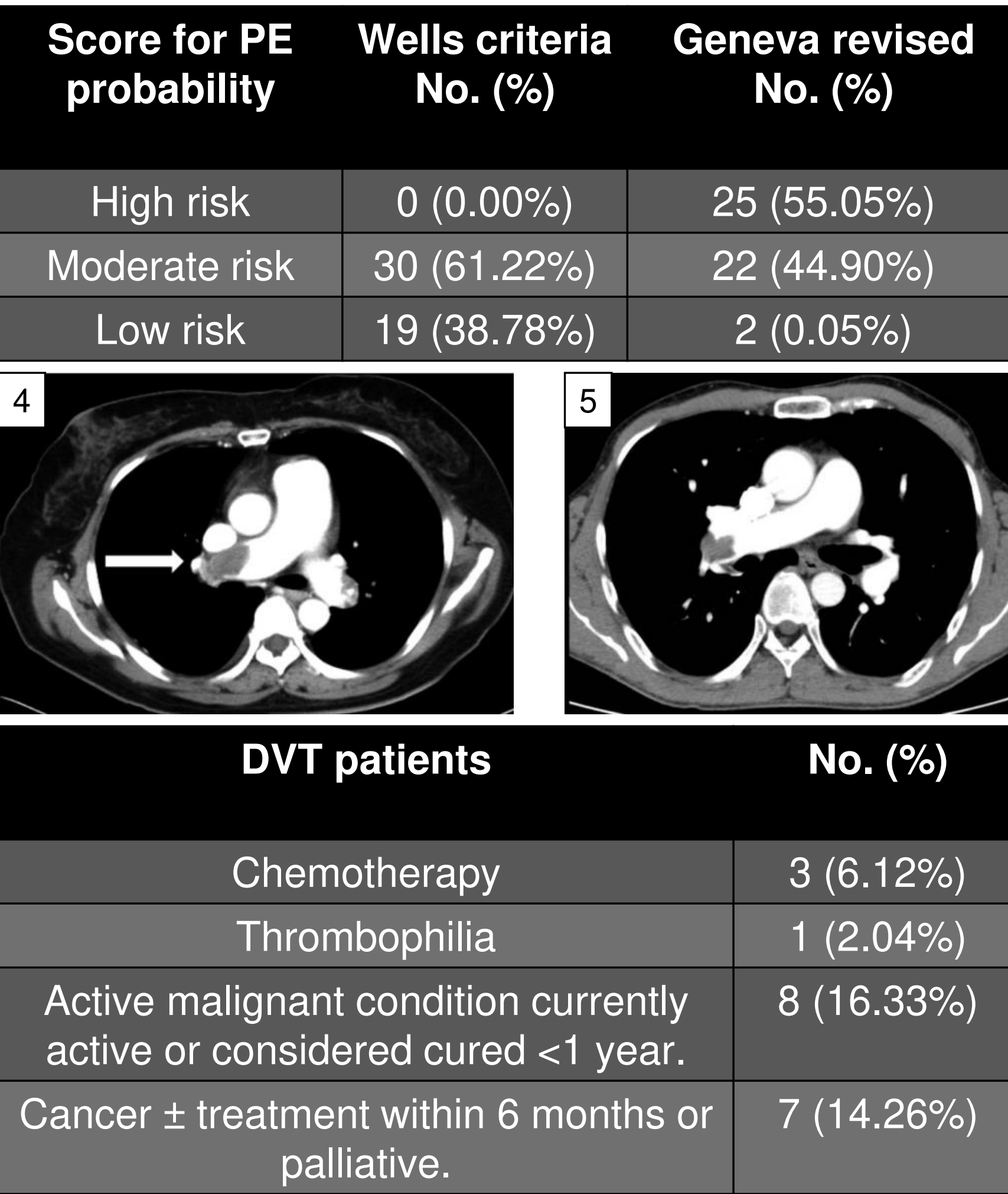

\section{CONCLUSIONS}

Doppler ultrasound is an effective, easy to use and non-invasive method to detect DVT, yet serial ultrasonography is generally recommended. Doppler ultrasound should be combined with clinical prediction rules for patient safety and comfort. 